\title{
PAUTAS PARA PUBLICAR EN LA REVISTA Comunicación Cultura y Política
}




\section{Presentación}

La Revista comunicación, cultura y política (ISSN: 2145-1494) es una publicación semestral de la Facultad de Humanidades y Ciencias Sociales, de la Universidad EAN, comprometida con la difusión de la producción, académica e investigativa en el área de las Ciencias Sociales, en particular, profundiza en las temáticas relacionadas con la comunicación, la cultura, la política y el entorno empresarial.

Su público objetivo son los profesionales, académicos, investigadores y estudiantes, que buscan actualizarse en contenidos relacionados con los ejes temáticos que aborda la publicación.

\section{Pautas para presentación de artículos}

\subsection{Tipología}

Los artículos que sean enviados a la Revista Comunicación, cultura y política, deben estar dentro de una de las siguientes categorías1:

\begin{tabular}{|l|l|}
\hline Tipo de artículo & Descripción \\
\hline $\begin{array}{l}\text { Artículos de investigación } \\
\text { científica y tecnológica }\end{array}$ & $\begin{array}{l}\text { Documento que evidencia resultados originales de un proyecto } \\
\text { de investigación concluido. La estructura generalmente utilizada } \\
\text { contiene cuatro apartes importantes: introducción, metodología, } \\
\text { resultados y conclusiones. }\end{array}$ \\
\hline Artículo de reflexión & $\begin{array}{l}\text { Documento que evidencia resultados de un proyecto de } \\
\text { investigación concluido, bajo una perspectiva analítica, } \\
\text { interpretativa o crítica del autor sobre un tema puntual. }\end{array}$ \\
\hline Artículo de revisión & $\begin{array}{l}\text { Documento resultado de una investigación terminada } \\
\text { donde se analizan, sistematizan e integran los resultados de } \\
\text { investigaciones publicadas o no publicadas, sobre un campo en } \\
\text { ciencia o tecnología, con el fin de dar cuenta de los avances y } \\
\text { las tendencias de desarrollo. Se caracteriza por presentar una } \\
\text { cuidadosa revisión bibliográfica de por lo menos 50 referencias. }\end{array}$ \\
\hline Artículo corto & $\begin{array}{l}\text { Documento breve en el que se evidencian resultados originales, } \\
\text { bien sean preliminares o parciales de una investigación científica } \\
\text { o tecnológica. }\end{array}$ \\
\hline Revisión de tema & $\begin{array}{l}\text { Es un documento de revisión crítica de la literatura, sobre un } \\
\text { tema puntual. }\end{array}$ \\
\hline Reporte de caso & $\begin{array}{l}\text { Documento que presenta los resultados de un estudio sobre una } \\
\text { situación puntual, para dar a conocer las experiencias técnicas y } \\
\text { metodológicas consideradas en un caso específico. Debe incluir } \\
\text { una revisión de literatura sobre casos análogos }\end{array}$ \\
\hline
\end{tabular}

\footnotetext{
${ }^{1}$ La tipología de artículos aquí presentada, se tomó de las especificaciones presentadas por Colciencias Publindex-.
} 


\subsection{Estructura general de los artículos.}

Los datos indispensables que debe incluir todo artículo postulado son:

- Nombre(s) completo(s) del autor(es).

- Filiación institucional actual.

- Correo electrónico - preferiblemente institucional o empresarial-.

- Breve biografía académica.

Además de ello se sugiere que el artículo se estructure de la siguiente manera:

- Título. Debe ser conciso para que describa el contenido del artículo en forma clara y precisa, de tal forma que el lector identifique el tema fácilmente.

- Resumen. Debe ser en español y no debe superar las 160 palabras. Se trata de una síntesis del objeto de estudio, los objetivos, la metodología y las conclusiones.

- Palabras clave. Deben oscilar entre los cinco y diez ítems. Deben ser remitidas en español.

- Cuerpo del artículo. Como elementos fundamentales debe contener: introducción, metodología, desarrollo del contenido, conclusiones y referencias bibliográficas.

\subsection{Formato de presentación de los artículos.}

- Formato: carta $(21.5 \mathrm{~cm}$ x $27.9 \mathrm{~cm})$

- Márgenes: Sup. $2 \mathrm{~cm}$. Inf. $2 \mathrm{~cm}$. Izdo. $2 \mathrm{~cm}$. Dcho. $2 \mathrm{~cm}$

- Fuente: Arial

- Tamaño de fuente: 12 puntos

- Interlineado: 1.5

- Procesador: Word

- Extensión del artículo: entre 17 y 25 páginas. 


\subsection{Otros aspectos a tener en cuenta.}

- Normas de citación:

La Revista emplea una adaptación de la American Psychology Association (APA) como norma en lo referente a estilo, citación, referenciación y presentación de figuras y tablas. Se sugiere utilizar como guía específica el Manual de citación y referenciación de la universidad EAN, disponible en http://editorial.universidadean.edu.co/

- Títulos y subtítulos:

Deben ir numerados con el sistema decimal $(1,2,3,3.1,3.2,3.2 .1$, etc.). No deben ir con mayúscula sostenida, solo con mayúscula inicial.

- Figuras y tablas:

Tanto las fotografías como las imágenes y tablas deben tener numeración consecutiva, título y su respectiva fuente. Estos, además de presentarse en el cuerpo del texto, deben enviarse en un archivo adicional en el formato de origen en el que fueron creados. La resolución debe ser de 300dpi.

- Referencias:

Se ubican al final del documento y deben organizarse por orden alfabético. Todos los textos, contenidos referenciados y autores que se mencionen en el cuerpo del texto deben registrarse en las referencias y viceversa.

\section{Sobre los derechos de autor.}

- Los artículos postulados no podrán tener ningún compromiso editorial de publicación, ni deben encontrarse en proceso de evaluación simultáneo por parte de otra publicación o entidad.

- En el caso de usar fotografía y/o imágenes, se deben enviar los respectivos permisos de uso y publicación de las mismas.

- El autor o autores, deberán autorizar la publicación de su texto a través del diligenciamiento y firma del formato de «Autorización de la publicación a favor de la Universidad EAN».

- Los artículos publicados en la Revista, podrán ser reproducidos con fines académicos, citando la fuente y el autor. El contenido de la Revista está bajo una licencia de Creative Commons Reconocimiento-NoComercial-SinObraDerivada 4.0 Internacional. 
- En cualquier caso, el Comité Científico y Editorial de la Revista entiende y declara que las opiniones expuestas por los autores, son de su exclusividad y responsabilidad.

\section{Proceso de evaluación}

Los artículos postulados a la Revista Comunicación, cultura y política son sometidos a un completo proceso de evaluación, que tiene como criterios generales de selección la pertinencia temática, la calidad científica, la originalidad, la claridad en la argumentación y el cumplimiento de los parámetros de presentación de artículos establecidos por la Revista, con el fin de garantizar la calidad y el rigor científico de la publicación; a continuación, describimos con detalle dicho proceso:

Una vez definidos tanto los ejes temáticos de las ediciones del año, como la proyección del calendario editorial por parte del Comité Editorial de la Revista, se procede a lanzar las respectivas convocatorias, de alcance nacional e internacional, para recepción de artículos.

Tras el cierre de la convocatoria, el Comité Editorial se reúne para realizar el proceso de verificación de requisitos iniciales de los artículos, con relación a su tipología, el cumplimiento de las pautas de presentación de artículos de la revista y el foco temático del mismo.

Luego de este primer filtro de evaluación se realiza la respectiva notificación a la totalidad de los autores y aquellos textos que han superado esta primera etapa pasan a la fase de revisión y evaluación en modalidad doble ciego, por parte de pares externos.

La selección de los pares externos se realiza en función de su conocimiento y experticia con respecto a la temática del texto a evaluar. Dicha búsqueda se realiza a través de la base de datos de colaboradores externos de la publicación -que se encuentra en constante actualización- y la base de datos de árbitros de Colciencias.

La evaluación se realiza mediante el formato establecido por la Revista, que se envía a los pares junto al texto, las indicaciones generales de diligenciamiento y la notificación de los plazos establecidos para realizar la respectiva revisión y evaluación.

Los dos ejes alrededor de los cuales se articula la evaluación son la estructura formal y la calidad del contenido, los cuales de dividen a su vez en una serie de elementos que se califican de forma numérica -de 1 a 5 , siendo 1 el menor valor y 5 el mayor-, y que en su suma final arrojan un puntaje que determina la valoración y el concepto frente a la publicación del artículo de la siguiente manera: 


\begin{tabular}{|c|c|l|}
\hline CALIFICACIÓN & VALORACIÓN & \multicolumn{1}{c|}{ CONCEPTO } \\
\hline $100-90$ & Excelente & Publicable y no requiere ajustes \\
\hline $89-80$ & Muy bueno & Publicable con ajustes mínimos \\
\hline $79-70$ & Bueno & Publicable con ajustes nivel medio \\
\hline $69-60$ & Aceptable & Publicable con ajustes significativos \\
\hline $59-0$ & No aceptable & No es publicable. \\
\hline
\end{tabular}

De acuerdo al concepto emitido por el par se procede a realizar la notificación a cada autor, la retroalimentación de las observaciones y sugerencias emitidas mediante la evaluación y la solicitud de ajustes, si se requiere. En este último caso, se determina un plazo específico de entrega y posteriormente se realiza un proceso de verificación de dichos ajustes, a cargo del par evaluador.

\section{Sobre plagio y autoplagio}

Se considera plagio la copia textual o parcial de ideas ajenas que se presentan como propias. Por lo tanto, se entiende como apropiación intelectual indebida; es una práctica proscrita por la ley, reprochada y repudiada por la sociedad.

tPor lo anterior, cada autor, en sus escritos, debe respetar el derecho que surge sobre ideas, criterios e incluso figuras, tablas, y en general, todo tipo de obras que se tomen de otros autores; es decir, debe darles su respectivo crédito.

En cuanto al autoplagio, se trata de las publicaciones anteriores elaboradas por autores, que a su vez, consideran que pueden utilizar información de estos materiales sin indicar que, primero, ya fueron publicados, y segundo, que es de su autoría. Esta práctica, desde cualquier punto de vista ético, es inapropiado y rechazado en el marco de la escritura científica.

Los artículos que incurran en cualquiera de estas dos situaciones -plagio o autoplagio-, no serán considerados, bajo ninguna circunstancia, para surtir el proceso de publicación en la Revista EAN. Dado el caso se realizará la respectiva notificación de rechazo, haciendo explícito el motivo.

La Revista Comunicación, cultura y política utiliza el software Safe Assign para la verificación de plagio y autoplagio en sus artículos.

\section{Información y contacto}

Para mayor información comunicarse a: revistas@universidadean.edu.co

Para remisión de artículos: http://journal.ean.edu.co/ 